JAVIERA NARANJO

COFUNDADORA

ORGANIZACIÓN OFICIOS VARIOS

SANTIAGO, CHILE

JAVIERA.NARANJOH@GMAIL.COM

\section{¿Qué entendemos cuando hablamos de artesanía?}

What do we understand when we talk about crafts?

Resumen. El presente texto invita a realizar un ejercicio reflexivo y propone una mirada crítica sobre el uso de conceptos que enuncian tipos de expresiones, prácticas y técnicas específicas circunscritas en pueblos y culturas determinadas. Se realiza una revisión de las nociones artesanía, arte popular y oficio, haciendo hincapié en su capacidad de enunciación a lo largo de la historia, reconociéndolas -en algunos casos- como encubridoras de formas de dominación cultural que se arrastran desde la colonización europea en nuestros territorios.

Palabras clave: arte popular, artesanía, oficio, prácticas, saberes.

\begin{abstract}
This text invites us to perform a reflective exercise, while it proposes a critical view on the use of concepts unveiled in different types of expressions, practices and techniques, circumscribed in specific social geographies and cultures. A review of the notions of crafts, popular art and trades is carried out, highlighting their enunciating capacity throughout history, recognizing them - in some cases - as cover-ups of forms of cultural domination that creep from European colonization in our territories. Keywords: crafts, craft, folk art, knowledge, practices.
\end{abstract}

Fecha de recepción: 05/07/2019

Fecha de aceptación: 05/10/2019

Cómo citar: Naranjo, J (2019)

¿Qué entendemos cuando hablamos de artesanía?

RChD: creación y pensamiento, 4 (7), 1-9

DOI: $10.5354 / 0719-837 \times .2019 .53822$
Revista Chilena de Diseño,

RChD: creación y pensamiento

Universidad de Chile

2019, 4(7)

http://rchd.uchile.cl 
...llama en la mente, pulso

tranquilo, sin alcoholes, mano tan

ágil como el alma, tan fácil como el

alma; un poco de rito y un poco de

juego, es decir, la seriedad del

padre componiendo y la alegría del

hijo al rematar el éxito...

Gabriela Mistral

La convocatoria de este número de la Revista Chilena de Diseño trata específicamente el tema de "lo tradicional" y la relación "Artesanía/Diseño", en ella se plantea que "el término artesanía es amplio, dinámico y complejo. Usado para denominar una disciplina, una categoría, un conjunto de prácticas fluidas, pero, sobre todo una manera de hacer". Esa complejidad de la que se esboza es una realidad presente que vuelve impreciso el entendimiento de la noción misma de artesanía, que abre la interrogante de si esta es la noción más adecuada para nombrar aquellas prácticas y objetos que denominamos como tal en nuestras vidas cotidianas.

A continuación, presentaré un apartado de la tesis que trabajo hace años para el Magíster de Estudios Culturales Latinoamericanos de la Universidad de Chile. Este texto no es el resultado de nada, más bien es parte de las divagaciones que han capturado mi pensamiento durante este tiempo y, por tanto, no pretendo comprometer a ninguna institución o académico con ellas. Solo quiero invitar a los lectores a realizar un ejercicio reflexivo en torno a nociones que utilizo en el ejercicio de mi quehacer como investigadora de oficios. La idea es dar una mirada crítica al uso de un concepto que enuncia tipos de expresiones, prácticas y técnicas específicas circunscritas en pueblos y culturas determinadas. Estas se han visto expresadas a lo largo de la historia de diversas formas, que dependen de las necesidades de quien realiza dicha enunciación, palabras que reconozco como encubridoras de formas de dominación cultural que se arrastran desde la colonización europea en nuestros territorios.

El estar atentos a las palabras que usamos es un ejercicio fundamental para quienes buscamos descolonizar nuestras prácticas culturales y los espacios en los que desenvolvemos nuestro quehacer. El uso de las palabras no es ingenuo, nombrar es crear, decretar. Como dice Silvia Rivera Cusicanqui (2018a) "la configuración abigarrada y colonizada del tejido social nos pone frente al hecho de que las palabras resultan insuficientes para desmontar los bloqueos epistemológicos y las penumbras cognitivas que nos invaden en los tiempos de crisis" (p.38). Esto hace complejo el ejercicio, sobre todo cuando la denominación de algunas prácticas específicas evidencia lo intricadas que están en nosotros formas de dominación que arrastramos, muchas veces sin percibir, replicando al nombrar poderosas fuerzas que se relacionan con el racismo y la dominación, dos asuntos tan característicos de aquellos que llegaron a nuestro continente hace más de 500 años atrás.

Entonces, ¿cómo nombrar, definir y entender que son aquellas prácticas, objetos, técnicas e individuos que hoy se reconocen dentro de la noción de artesanía? En la actualidad, es dicha categoría la más usada para nombrarlos, pero a lo largo de la historia han sido otras palabras las utilizadas para referirse a estos mismos saberes y prácticas. Como curiosidades en los primeros años de la conquista o artes populares en la primera mitad del siglo XX. Pero ¿qué se trata de nombrar cuando evocamos estas palabras? 
Existen saberes que ha creado el ser humano a lo largo de la historia para satisfacer ciertas necesidades que surgen en su relación con el entorno, como una apropiación y adaptación histórica de los habitantes en cada uno de los territorios. Al presentarse necesidades comunes a lo ancho del planeta, estos saberes se desarrollaron de manera paralela en diferentes lugares, reconociéndose líneas comunes en diversos pueblos y culturas. Dichos saberes con el paso del tiempo se perfeccionan y particularizan, así, es posible encontrar cestería, alfarería, orfebrería, entre otros muchos, con las peculiaridades que determina el entorno.

Son estos saberes los que se traspasan de generación en generación dentro de las familias y comunidades, los que tienen técnicas y prácticas asociadas que son particulares del saber específico que se ejecuta, y los que responden a las diversas organizaciones sociales, políticas y económicas que surgen a lo largo de la historia. De esta forma, es imposible entenderlos sin sus contextos cercanos. No es lo mismo el desarrollo de estos saberes en la época prehistórica, prehispánica, en la Edad Media, en la Colonia o en la época contemporánea. Sin embargo, puede construirse una genealogía de estos que entrecruza todas las épocas, mientras es la práctica misma con su técnica aquello que se traspasa y perfecciona a lo largo de los años.

Al momento de nombrar estas prácticas y saberes se reconocen dos perspectivas para entenderlos, una productiva y otra sociocultural. Cuando se pone atención a los modos de producción de estos saberes y prácticas es adecuado hablar de artesanía, ya que lo artesanal refiere a un sector productivo que se organiza en talleres constituidos por un maestro y sus aprendices, donde existe una baja producción de objetos para comercializar o intercambiar. Lo artesanal es un modo de producción, entonces, podemos hablar de zapatos hechos de manera artesanal, miel hecha de manera artesanal, libros hechos de manera artesanal, esto en contraposición a una producción industrial de los objetos. La particularidad del trabajo artesanal es que, al estar hecho a mano, cada una de las piezas que se realiza se vuelve única e irrepetible. Se genera un sello particular del trabajo de cada uno de los talleres que lo realizan. Incluso en aquellos donde en alguna de sus fases se ocupa maquinaria, pero la mano todavía es la principal gestora de la manufactura.

Y, por otro lado, está la perspectiva sociocultural que tiene relación con las manifestaciones y significados particulares que surgen en un territorio y pueblo al momento de resolver las necesidades que se tienen en el habitar. Esto genera una especificidad heterogénea en el planeta, forja una rica diversidad de respuestas ante las mismas necesidades humanas. De esta forma, un agricultor peruano no es igual que un agricultor japonés, igual para el caso de un médico, criancero de animales, recolectores, alfareros o tejedores, los que a pesar de satisfacer las mismas necesidades humanas crean formas diversas de respuesta.

En la actualidad se utiliza el término artesanía para referirse a estas dos perspectivas, sin embargo, al estar emparentado el término a un entendimiento de estas prácticas y saberes desde un aspecto productivista, la palabra misma deja afuera en su nominación todo lo que se refiere a la mirada sociocultural que también la constituye, y si bien hoy existe un intento desde las instituciones que trabajan en estos temas de abarcar el término de manera más amplia, pareciera que el ejercicio se vuelve forzado y poco claro ante expresiones culturales tan colmadas de información y memoria. 
Su utilización deja en evidencia la perspectiva desde donde miramos en nuestra época y en nuestras sociedades occidentalizadas. Pareciera ser que el ámbito productivo es lo fundamental para entender todo este entramado de prácticas, humanos, conocimientos, territorios, técnicas, materias primas y formas de estar/habitar en el mundo. Lo artesanal devela la mirada epistemológica de los tiempos actuales, habitamos en una sociedad construida desde un experimento neoliberal que pareciera no poder construir fuera de las lógicas de la productividad, como si las relaciones del hacer y la creación solo pudieran ser válidas desde el intercambio productivista y mercantil.

Ante la insuficiencia del término artesanía, principalmente por su reduccionismo ante esta amplia realidad que intenta nombrar, pensé -en esta búsquedaque quizás la idea de arte popular podría hacer mayor justicia a estas prácticas y formas de vida. El uso de la noción de arte popular corresponde a una época determinada y a un período de tiempo específico de Chile y el continente. En su composición alberga dos ideas fuertes: por un lado, el arte, noción que nace en Europa y que define formas particulares de expresión humana; y, por otro, lo popular, este apellido tan característico de una época política y social. El arte es uno de los grandes relatos que se recicla de la modernidad europea. Este se desarrolla como concepto en Europa durante el siglo XVI y no es una esencia o un destino al que estaba sometido el ser humano, sino que es una idea que se construye y que ha perdurado por años. Es en la modernidad que se alzó la idea sobre el arte y donde se construyó una narrativa sobre el arte del pasado, presente y futuro que se acomodará a la realidad occidental, donde las expresiones culturales adquirieron una nueva significación. Cuando se produce esta separación, el artista de esta nueva era, que se conocerá como Renacimiento, se posiciona socialmente de forma diferente, sobre todo por la relación que comienza a sostener con el mercado.

El burgués, este nuevo actor social que surge con la modernidad, al obtener posesiones materiales y, por tanto, estatus, desafió el ordenamiento social anteriormente fundamentado, lo que trajo consecuencias directas para el entendimiento del arte. Así, la nueva concepción asociada al concepto de genio se encuentra a su vez unida a los comienzos de una economía básicamente capitalista, a la libre competencia y a un deterioro de nociones religiosas tradicionales, todo en favor de una mayor conciencia sobre las realidades terrenas (Fernández,1972).

El escritor paraguayo Ticio Escobar, quien a través de su libro El mito del arte y el mito del pueblo busca comprender las implicancias de la modernidad y las relaciones entre lo popular y lo erudito en el arte de América Latina, entrega un desglose conceptual que se agradece enormemente al momento de querer aproximarse a estos temas desde un punto de vista teórico. El autor expone que el concepto de arte que la teoría ilustrada propone parte del supuesto de que hace miles de años la humanidad entera produce esas formas sensibles, cuyo juego funda significaciones. El modelo universal de arte aceptado, propuesto e impuesto es el correspondiente al producido en Europa en un período históricamente muy breve. A partir de entonces, lo que se considera realmente arte es el conjunto de prácticas que tienen las notas básicas de él, tales como la posibilidad de producir objetos únicos e irrepetibles que expresen el genio individual y, fundamentalmente, la capacidad de exhibir la forma estética desligada de las otras formas culturales y purgada de utilidades y funciones que oscurezcan su nítida percepción (Escobar, 2008). 
Es en esta época cuando aparece la fijación por el artista, personaje único e innovador. Es probablemente, entonces, cuando el arte comienza a ser considerado como una manifestación de la personalidad individual, un resultado de la inspiración, concediéndose cada vez mayor interés a aspectos de índole emotiva y no puramente técnica. El énfasis en el manejo de los instrumentos cede ante la importancia otorgada a la individualidad del artista, circunstancia que, por cierto, todavía matiza nuestra apreciación contemporánea del arte (Fernández, 1972). De esta forma, se descalifica cualquier forma y práctica que se escape del modelo eurocéntrico y, como explica Escobar, se desconoce aquel supuesto tan proclamado por la historia oficial: el arte es fruto de cada época y don de todas las sociedades.

De esta forma, en América el arte será entendido dentro de un mito, para Escobar (2008), los conceptos no bastan para resolver las paradojas del arte y justificar la vigencia de este modelo único por tantos años. Por lo tanto, es necesario recurrir al Mito del arte, entendido este como: un extracto de experiencias sociales cuajadas al costado del tiempo. Para el autor, los mitos constituyen esquemas de interpretación de lo real y resguardo contra los estragos de la contingencia. Señala:

El poder que tiene el mito de capturar momentos y liberarlos de sus condicionamientos - de fundar arquetipos y sustraerlos del cambio- deja a menudo figuras coaguladas, pesos muertos que lastran el devenir social. La oposición entre esos residuos estancados y las formas míticas movilizadoras de nuevos sentidos anima los procesos culturales e impulsa desarrollos desiguales, distintos ritmos. (p.30)

El autor propone que con frecuencia la cultura dominante manipula ideológicamente el mito, se sirve de su capacidad para paralizar ideas, imágenes y valores e inscribirlos en un nivel extratemporal que los fundamente. Así, se usa el mito para eternizar arbitrariamente aspectos que convengan al discurso de la dominación y se crea un discurso que pretende absolutizar las formas artísticas en las que se siente representado y justificado; intenta convertirlas en esencias, principios de un canon absoluto, ideal de toda práctica que aspire al título de arte. Como explica Rojas Mix (2015):

...hasta entrado el siglo XX nadie concebiría, ni artistas, ni filósofos, que creaciones de pueblos distantes pudiesen tener un valor artístico. Para ellos solo era arte aquel fundado en la tradición clásica, creado en Europa por el «genio europeo»; el resto era estimado, a lo sumo, como curioso, obra de pueblos bárbaros y «groseros» que, aun cuando pudiese despertar el interés histórico distaba de tener virtud artística. (p. 223)

América introduce este modelo de arte, por lo que aplica una vez más la copia e importación. Las elites dominantes de América, en base a la vieja tendencia de trasplantar ideas, no advierten la posibilidad de que las sociedades indígenas y mestizas, como parte de otro sistema cultural, sean capaces de crear arte. De esta forma, toda expresión cultural creada desde tierras americanas será vista en contraposición al modelo asumido de arte y, por tanto, denostada por no encajar en el modelo establecido. Las expresiones 
culturales americanas serán nombradas por conceptos ajenos y enfrentadas a ese modelo mítico, al recurrir nuevamente a Escobar (2008), el arte popular aparece empobrecido y mutilado: gran parte del menosprecio que sufren sus expresiones se infiere del mito de que determinadas prácticas producidas en Europa, y después en los EE.UU., constituyen, por aparentemente superiores, el único parámetro de lo que debe ser el arte.

De esta forma, Escobar permite comprender que el indicar dichas expresiones culturales con la denominación de arte popular no solo busca definir los objetos creados o las formas en que se producen, sino que se enuncian manifestaciones culturales que en gran parte realizan las poblaciones rurales e indígenas del continente; poblaciones subalternas que han experimentado una historia de colonizaciones tanto territoriales como conceptuales. En consecuencia, la utilización de estas ideas y palabras evidencia formas de dominación y comprensión del otro.

Al relacionar estos saberes y prácticas con la idea del arte se entra en un espacio de definiciones confusas. La idea de arte desde sus inicios trae una carga de distinción. No todo se podrá denominar como tal. Y la misma noción de arte popular se presenta como una negación, es arte, pero no a secas, sino que es un arte acompañado de un apellido que no le permite entrar por la puerta ancha al mundo de la creación. El arte popular se vuelve desde su denominación un arte menor, un arte imposibilitado de ser. La nominación de estas prácticas es un problema que Escobar (2008) ya advirtió en la década de los ochenta, problema del que aún hoy no podemos desprendernos, el término arte popular es también impreciso para expresarlas, dice el autor:

A la hora de considerar lo artístico popular latinoamericano, aparece enseguida el escollo de una carencia: la falta de conceptos para nombrar ciertas prácticas propias y el escaso desarrollo de su pensamiento crítico capaz de integrar las diferentes producciones culturales en una comprensión orgánica. Aunque se parta del bien nutrido cúmulo de conceptos de la teoría universal, siempre habrá categorías que, gestadas en otras historias, no encastren en el casillero de experiencias diferentes y deban ser readaptadas o sustituidas en un proceso de inevitables reformulaciones. (p. 27)

Las implicancias del arte popular - o de las actualmente llamadas artesaníaspresenta un desafío que significa comprenderlas de manera amplia y orgánica, en la actualidad ambas nominaciones me resultan reductivas ante el universo que significa todo aquello que se reconoce como tal. Las palabras no solo refieren al objeto, $\mathrm{o}$ al individuo que los realiza, sino que intenta abarcar todo lo que concierne a la creación de estos, el entorno, la técnica, las formas de aprendizaje, los usos y costumbres asociados a su creación y utilización. Ante esta disyuntiva, ante la incomodidad que me generan la idea de artesanía o de arte popular, propongo la noción de oficio para nombrar y describir estos saberes y prácticas, adscribo a la corriente de pensadores que los denominan como tal, la siento liviana en comparación a todas las demás que funcionan en estos tiempos como sinónimos. La artesanía da cuenta de un sistema de producción, pero decir artesanía no es decir saber, es decir producción. La palabra en sí no evoca al conocimiento que existe tras él. Sin embargo, existen talleres artesanales de diferentes oficios: taller artesanal alfarero, zapatero, 
textil. Es posible abarcar el mundo de los oficios desde un plano artesanal. Cuando al investigar se busca poner la atención en el saber, la idea misma de artesanía se vuelve mezquina y poco precisa, ya que el modo de producción puede variar según el sistema social y económico que exista en determinado momento de la historia, sin embargo, todo grupo humano, donde sea que se sitúe dentro del planeta, tanto en tiempo y espacio, genera saberes que desarrolla y sistematiza para cubrir sus necesidades. Estos son los oficios, es una palabra que se puede acomodar, sin una carga de dominación como ocurre con la idea de arte popular, y es que porqué tendríamos que llamarle arte a estos saberes, si lo que se pretende es referirse a formas de vida, las que conllevan un estar, una ocupación del tiempo diferente a la que propone el régimen neoliberal-capitalístico ${ }^{1}$, una relación con el entorno, con las materias primas, con el traspaso del saber y las comunidades que lo contienen. Su valor tiene fuerza en su práctica, en su hacer. Su gracia en las particularidades que le otorga cada individuo que la realiza, mientras más se practica, más se acerca a la maestría y por tanto al buen oficio.

Por ejemplo, el saber de la curación, del sanar enfermedades humanas, es un saber antiguo que se ha desarrollado a lo largo de los años y en todas las sociedades humanas que existen en el planeta. El cómo, quién y con qué ha variado, pero es un saber que se ejecuta sobre cuerpos humanos que tienen características similares, lo que hace que al encontrarse dos personas que oficien ese saber puedan intercambiar conocimientos con respecto a la práctica que ejecutan. Otros ejemplos como este se pueden encontrar en la cestería, cocina, construcción, alfarería, agricultura, todos oficios que se han pulido con el paso del tiempo para generar una expertiz en ciertos individuos que se constituyen como maestros de su saber.

Llego a esta noción principalmente por el trabajo de Gabriela Mistral, es ella quien me presenta estos saberes y estas prácticas enmarcadas en la idea del oficio. Esteban Scarpa realizó una generosa compilación llamada Grandeza de los Oficios, que cuenta con la mayoría de los textos en que la autora expuso sus ideas con respecto a ellos. Ahí Mistral se refiere al oficio como si diera cuenta de una filosofía de vida, de una brújula ética que guía toda acción humana, entendido como el espacio en que todo ser humano se sitúa para hacer su aporte dentro del entramado social que habita. Dice en su texto "Sobre el Oficio": "Muy torpe, el uso corriente de juzgar a hombre o mujer fuera de su oficio. Fulano es mal abogado, pero excelente persona" (p. 14). O, si se trata de un herrero:

No sabe lo suyo, pero es un santo. No, no hay probidad que pueda quedarse afuera del oficio. Quien cojee en su profesión, cámbiela, sencillamente, pero hínquese en otra donde pueda alcanzar el último tramo y ser probo, partiendo de su oficio como de un centro. Eje de la vida, el oficio. Que las demás cosas, consideración social, dinero, etc. sean radios que de ahí partan. (p. 14)

Mistral entiende la dignidad humana desde la ejecución del oficio, cuestión que explica más allá de la producción del objeto, tiene que ver con el trabajo consciente de las técnicas, del conocimiento de la historia de lo que se crea, de la dedicación completa al hacer, a la práctica. Desde su mirada el perfeccionamiento humano conlleva el perfeccionamiento del oficio, y entonces, corresponde entregar la vida misma a la autoformación permanente del quehacer. Dice: “Damos prueba de nosotros en nuestra manera de amistad y de amor, en la elección
1. Se utiliza la noción de sistema neoliberal-capitalístico desde lo propuesto por la psicoanalista Suely Rolnik (2019) en su libro Esferas de la insurrección. Apuntes para descolonizar el inconsciente. Ahí explica: "Con sucesivas transmutaciones, este régimen viene perdurando y sofisticándose desde finales del siglo XV, la época de su fundación. Su versión contemporánea -financierizada, neoliberal y globalitaria- empieza a formarse en el paso del siglo XIX al siglo XX y se intensifica luego de la primera guerra mundial, cuando se internacionalizan las capitales. Pero a partir de mediados de la década de 1970 llega a su poder pleno, al afirmarse contundentemente $-\mathrm{y}$ no por casualidad- luego de los movimientos micropolíticos que sacudieron el planeta durante la década de 1960 y 1970. Durante ese período -mediados de la década de 1970-se concentran los primeros pasos de un trabajo de desciframiento del actual rumbo de este régimen en su compleja naturaleza, es decir, de los principios que la rigen y de los factores que engendran las condiciones para su consolidación.

(...) Su punto de partida es uno de los temas del orden del día en esta construcción colectiva: el modo de relación entre el capital y la fuerza vital, propio del régimen en su actual versión, y por entero distinto a su modo fordista. En esta nueva versión, el ámbito de la fuerza vital de la cual se alimenta el capitalismo ya no se reduce a su expresión como fuerza de trabajo, lo que implica una metamorfosis radical de la propia noción de trabajo. Eso se acompaña de una paulatina dilución de la forma del Estado democrático de derecho, de la cual dependían las leyes laborales propias del régimen en su versión anterior. (...) Si bien la base de la economía capitalista es la explotación de la fuerza de trabajo y de la cooperación inherente a la producción para extraer plusvalía de ellas, dicha operación -a la que podemos denominar "proxenetización" o "cafisheo" para asignarle un nombre que diga más precisamente la frecuencia vibratoria de sus efectos en nuestros cuerpos- fue cambiando de figura con las transfiguraciones del régimen en el transcurso de los cinco siglos que nos separan de su origen. En su nueva versión, es de la propia vida que el capital se apropia; más precisamente, de su potencia de creación y transformación en la emergencia misma del impulso -es decir, en su esencia germinal-, como así también de la 
cooperación de la cual dicha potencia depende para efectuarse en su singularidad. La fuerza vital de creación y de cooperación es así canalizada por el régimen para construir un mundo acorde con sus designios. En otras palabras, en su nueva versión, es la propia pulsión de creación individual y colectiva de nuevas formas de existencia, y sus funciones, sus códigos y sus representaciones lo que el capital explota, haciéndose ella su motor. Por eso la fuente de la cual el régimen extrae su fuerza deja de ser exclusivamente cultural y subjetiva -por no decir ontológica-, lo cual la dota de un poder perverso más amplio, más sutil y más difícil de combatir" (pp. 26-28). de un partido político o de una fe; pero todos ésos son testimonios parciales o vagos; el cómo encuadernamos un libro o damos nuestra clase en una escuela, nos dice eso, si da el duplicado de nuestro semblante" (Mistral, 1927, p.13). Al entender estos saberes y prácticas desde esta perspectiva, pienso, no se deja espacio para la folklorización, no se habla de un otro ajeno a nuestra realidad, los oficios, los saberes, las técnicas, son aprendidos y resguardados por todos quienes entendamos su quehacer con el compromiso que conlleva ser parte de un colectivo. No es solo un modo de producción para conseguir beneficios mercantiles, tampoco es creación que busque deleitar estéticamente a otros, son sabidurías que a lo largo de nuestra existencia humana se han creado, pulido, traspasado, porque las necesitamos para habitar nuestros entornos. Son gestos que contienen memoria y sentido para las comunidades que las realizan, son enlaces de sabidurías que también nos pertenecen porque somos parte de la misma especie y vivimos e interactuamos inevitablemente con el territorio.

Y entonces, al mirar desde esta perspectiva estos saberes y prácticas culturales, la investigación que se hace de ellos cambia, por lo menos para mí, da un giro, advierto que en mi hacer hurgo otras formas de organización social, otras formas de entender el tiempo y espacio en que nos movemos. Observo con mayor claridad la amenaza que significa el régimen neoliberal-capitalístico para estas formas de vida, que con su idea de desarrollo no encaja en las lógicas en las que se han tramado por años estos saberes.

Actualmente, los espacios íntimos de traspaso del conocimiento y desarrollo de estas formas de vida son tensionadas, existe una jerarquización de las capacidades cognitivas, se asume que aquellos conocimientos enmarcados dentro de los espacios formales de educación son más importantes y valiosos que aquellos enseñados y traspasados en las familias y comunidades de manera tradicional. Como explica Silvia Rivera Cusicanqui (2018b) ha existido un disciplinamiento cruel en nuestras actuales sociedades occidentalizadas, con una mirada cargada de desprecios coloniales se asume que campesinos, indígenas y trabajadores manuales son ignorantes, son menospreciados sus saberes, prácticas y técnicas por no parecer útiles para los tiempos actuales. Este tema lo he conversado de diversas formas en los territorios donde me ha tocado trabajar, y cuando se supera la angustia que provoca, se nos presenta como una oportunidad de pensarnos, de pensar nuevas estrategias de resistencia ante las lógicas perversas del régimen. Y entonces, es en este escenario donde resulta fundamental revisar las formas en que nombramos, porque es verdad que al nombrar creamos, y corresponde, si respetamos estos saberes y prácticas antiguas, dejar de encubrir en su enunciación formas de dominación que muchas veces se cuelan en nuestro hablar para provocar poderosos conjuros en los individuos y comunidades que los resguardan desde tiempos inmemoriales en sus territorios. 


\section{Referencias}

Escobar, T. (2008). El mito del arte y el mito del pueblo. Cuestiones sobre arte popular. Santiago: Ediciones Metales Pesados.

Fernández, J. (1972). Arte mexicano: de sus orígenes a nuestros días. Ciudad de México: Editorial Porrua. Mistral, G. (1927). "Sobre el Oficio”. En R. Esteban Scarpa (Ed.), Grandeza de los Oficios. Santiago: Editorial Andrés Bello.

Rivera Cusicanqui, S. (2018a). Un mundo ch'ixi es posible. Ensayos desde un presente en crisis. Buenos Aires: Ediciones Tinta Limón.

Rivera Cusicanqui, S. (2018b). Recuperado en http:// oficiosvarios.cl/respirar-el-pensamiento/

Rojas Mix, M. (2015). América Imaginada. Santiago: Editorial Pehuén.

Rolnik, S. (2019). Esferas de la insurrección. Apuntes para descolonizar el inconsciente. Buenos Aires: Ediciones Tinta Limón. 